\title{
4
}

\section{CRISES ECONOMICA E SANITÁRIA: NOTAS DE CONTINUIDADE}

\author{
Economic and sanitary crises: continuity notes
}

\author{
Letícia Batista Silva* \\ https://orcid.org/0000-0003-2520-2621 \\ Marina Monteiro de Castro e Castro** \\ https://orcid.org/0000-0002-9027-4659 \\ Rodriane de Oliveira Souza*** \\ https://orcid.org/0000-0003-0932-1487
}

\section{RESUMO}

Neste ensaio partimos do pressuposto de que a vida em sociedade no Brasil em tempos de pandemia é uma expressão do que já vivenciávamos antes do SARS-CoV-2. O lucro acima da vida (vida de trabalhadoras e trabalhadores) já era uma ideia-força presente há longo tempo no cenário nacional. A base metodológica do texto é uma revisão de literatura que associa produções que analisam o contexto pandêmico com autores que debatem as repercussões das crises cíclicas do capital e autores que situam o debate do exercício profissional. Nesse sentido, o objetivo deste ensaio é discutir a compreensão de que há uma crise econômica e social que precede e atravessa a crise sanitária provocada pela pandemia e, por fim, buscamos apresentar algumas implicações desse processo no exercício profissional em Serviço Social no campo da saúde.

\section{PALAVRAS-CHAVE}

Crise sanitária. Crise e COVID-19. Crise econômica e direitos sociais. Serviço Social e saúde.

\footnotetext{
*Assistente Social. Doutora em Serviço Social. Pesquisadora em Saúde Pública Associada e Professora da Escola Politécnica de Saúde Joaquim Venâncio da Fundação Oswaldo Cruz (EPSJV/FIOCRUZ). Professora Adjunta da Escola de Serviço Social da Universidade Federal Fluminense (UFF, Niterói, Brasil). Rua Prof. Marcos Waldemar de Freitas Reis, $\mathrm{S} / \mathrm{N}^{\circ}$, Campus do Gragoatá, Bloco E, São Domingos, Niterói (RJ), CEP: 24210-201. E-mail: leticiabatistas@gmail.com.

${ }^{* *}$ Assistente social. Doutora em Serviço Social. Professora da Faculdade de Serviço Social da Universidade Federal de Juiz de Fora (FSS-UFJF, Juiz de Fora, Brasil). Campus Universitário, Rua José Lourenço Kelmer, s/n - São Pedro, Juiz de Fora (MG), CEP 36036-900. E-mail: marinamcastro@gmail.com.

${ }^{* * *}$ Assistente Social. Mestre em Serviço Social. Professora Assistente da Faculdade de Serviço Social da Universidade do Estado do Rio de Janeiro (FSS/UERJ, Rio de Janeiro, Brasil). Rua São Francisco Xavier, n. 524, Pavilhão João Lyra Filho, $8^{\circ}$ andar, Bloco D, Sala 8030-2, Maracanã, Rio de Janeiro (RJ), CEP: 20550-900. Email: rodriane.o.souza@gmail.com.
}

DOI 10.22422/temporalis.2021V21n41p34-52

(cc) B BY Commons Atribuição 4.0 Internacional (https://creativecommons.org/licenses/by/4.o/deed.pt_BR), que permite copiar e redistribuir o material em qualquer suporte ou formato, bem como adaptar, transformar e criar a partir deste material para qualquer fim, mesmo que comercial. O licenciante não pode revogar estes direitos desde que você respeite os termos da licença. 


\begin{abstract}
In this essay, we assume that life in society in Brazil in times of pandemic is an expression of what we were already experiencing before SARS-CoV-2. Profit above life (workers' and workers' lives) was already a forceidea present for a long time on the national scene. The methodological basis of the text is a literature review that associates productions that analyze the pandemic context with authors who debate the repercussions of the cyclical crises of capital and authors who situate the debate on professional practice. In this sense, the objective of this essay is to discuss the understanding that there is an economic and social crisis that precedes and crosses the sanitary crisis caused by the pandemic and, finally, we seek to present some implications of this process in the professional practice of Social Work in the field of health.
\end{abstract}

\title{
KEYWORDS
}

Sanitary crisis. Crisis and COVID-19. Economic crisis and social rights. Social Work and health.

\section{INTRODUÇÃO}

A pandemia do novo coronavírus no Brasil tem apresentado contornos dramáticos de uma crise sanitária e humanitária que já levou à morte mais de 487 mil $^{1}$ pessoas. Chegamos em 2021 avançando para um colapso nacional do sistema de saúde, com pessoas morrendo por falta de oxigênio ou aguardando em filas por leitos de enfermaria e de Unidades de Tratamento Intensivo (UTI). A doença decorrente do vírus, a COVID-19, tem se mostrado implacável, assim como o vírus que a gera - que tem se apresentado com alta capacidade de modificação. No Brasil, esse processo se agrava com o negacionismo do governo federal expresso em uma não-ação-ativa no enfrentamento da COVID-19, colocando em questão as principais estratégias de contenção do vírus - o isolamento social e a vacinação.

Como apontam os estudos de Barreto et al. (2020) e Garcia e Duarte (2020), o isolamento social tem por objetivo o controle do contágio, o que significa uma ação direta no sentido de diminuir o número de contaminados e, por conseguinte, o número de internações e mortes. Em que pese os apontamentos da ciência, vivenciamos, cotidianamente, uma campanha especialmente na figura do presidente da república, no sentido de negar as evidências científicas sobre a importância do uso da máscara e do isolamento social como ferramentas que provocam a diminuição de mortes. Países como Nova Zelândia e China são experiências exitosas no controle da contaminação por utilizarem o isolamento social combinado com testagem em massa. Essa associação de esforços não aconteceu no enfrentamento da COVID-19 no Brasil.

Sobre a questão da vacina, as respostas do governo federal ocorrem no sentido inverso, desconsiderando a centralidade da implementação de um plano de vacinação para a imunização da população. A opção inicial (que aconteceu com atraso) foi por uma vacina preferencial, que teve como impacto o não desenvolvimento de um planejamento exequível de imunização em tempo oportuno.

Em termos mundiais, conforme dados ${ }^{2}$ da Our World in Data (2021), podemos observar, por exemplo, que o Chile imunizou com a primeira dose $61 \%$, e a imunização completa atinge

\footnotetext{
${ }^{1}$ Dados referentes a 13/06/2021.

2 Dados referentes a 12/06/2021.
}

Temporalis, Brasília (DF), ano 21, n. 41, p. 34-52, jan./jun. 2021. | ISSN 2238-1856 
um percentual de $44 \%$ da população. O Uruguai tem imunização completa de $34 \%$ de sua população e $60 \%$ com a primeira dose. No Reino Unido, $62 \%$ imunizou com a primeira dose e $45 \%$ com imunização completa. O que unifica esses países é a utilização de um plano amplo e planejado de imunização, que comporta a compra de diferentes vacinas para imunizar a população (especialmente os grupos de risco) com celeridade.

Olhando para um panorama global o que se encontra é que apenas $12,7 \%$ da população mundial recebeu pelo menos uma dose das vacinas de prevenção a COVID-19 e o percentual de pessoas em países de baixa renda receberam uma dose é de apenas 0,8\% (OUR WORLD IN DATA, 2021).

Enquanto isso, o Brasil, país com segundo maior número de mortes no mundo, vacinou apenas $11 \%$ com primeira e segunda dose e apenas $25 \%$ da população com a primeira dose. Apesar do Sistema Único de Saúde (SUS) ser reconhecido internacionalmente por possuir um dos sistemas mais eficazes de imunização, não há vacinas disponíveis para tal efetivação no que tange ao novo coronavírus. Está no horizonte brasileiro a produção das vacinas que, no momento, estão sendo envazadas pela Fundação Oswaldo Cruz (Fiocruz) e pelo Instituto Butantan, mas se trata de uma previsão de início de produção somente para o segundo semestre de 2021.

O real enfrentamento da COVID-19 passa pela realização de muitas etapas complexas e simultâneas que deveriam, conforme a Lei nº 8,080/1990 (BRASIL, 1990), ser coordenadas pelo governo federal. Como afirma Guimarães (2020), o enfrentamento à COVID-19 é complexo e atinge diferentes e complementares planos de intervenção: a abordagem clínica, o terreno epidemiológico e a vida em sociedade. Sobre este último ponto, temos alguns destaques.

Neste ensaio partimos do pressuposto de que a vida em sociedade no Brasil em tempos de pandemia é uma expressão do que já vivenciávamos antes do SARS-CoV-2. O lucro acima da vida (vida de trabalhadoras e trabalhadores) já era uma ideia-força presente desde há tempos no cenário nacional. A diferença é que a COVID-19 deixa essa questão ainda mais explícita.

No contexto de uma pandemia mundial as desigualdades próprias do modo de produção capitalista ficam ainda mais aparentes. Num primeiro momento, ouvia-se dizer, principalmente na grande mídia corporativa, que o novo coronavírus era democrático, pois atinge todas as classes sociais. Essa afirmação mostrou-se falaciosa, pois obscurece o caráter de classes presente na determinação social do processo saúde-doença. Os números de contaminação e mortalidade por COVID-19 expressam uma crise sanitária, mas também reafirmam a crise cíclica do capital (MANDEL, 1982), assim como suas respostas em termos de recrudescimento das condições sociais de reprodução da classe trabalhadora.

Conforme descrito por Mandel (1982), Mészáros (2002) e Harvey (2002), a crise cíclica do capital tem como traços gerais a queda das taxas de lucro, dos níveis de produtividade e consumo; o esgotamento do padrão taylorista/fordista; a flexibilização dos processos produtivos, dos mercados e da força de trabalho, tendo como desfecho o desemprego estrutural e a hipertrofia da esfera financeira, que ganha relativa autonomia frente ao capital produtivo. As análises realizadas por estes autores permanecem atuais na medida 
em que observamos os efeitos das crises globais vivenciadas mais recentemente, em 20082009 .

Voltemos à particularidade brasileira. Acima falamos do isolamento social como uma ferramenta de controle da contaminação e da mortalidade, contudo, nossa referência ao isolamento social não se refere apenas à dimensão individual do ato, mas sim à sua mínima sustentação como possibilidade real, ou seja, do papel que o Estado tem em criar mínimas condições de sustentação econômica para a realização do isolamento.

Nessa esteira, buscando articular as crises econômicas e a crise sanitária causada pelo SARS-CoV-2. O objetivo deste ensaio é discutir a compreensão de que há uma crise econômica e social que precede e atravessa a crise sanitária provocada pela pandemia e, por fim, apresentar algumas implicações desse processo no exercício profissional em Serviço Social no campo da saúde. A base metodológica do texto é uma revisão de literatura que associa produções que analisam o contexto pandêmico com autores que debatem as repercussões das crises cíclicas do capital e autores que situam o debate exercício profissional. Nosso esforço é no sentido de articular elementos pré-COVID-19 com o contexto atual.

\title{
CRISES ECONÔMICA E SANITÁRIA: FACES DE UMA MESMA MOEDA
}

Chegamos a março de 2021 imersos em um crítico cenário nacional, conforme Boletim Extraordinário do Observatório COVID-19 (FUNDAÇÃO OSWALDO CRUZ, 2020, p. 1):

\begin{abstract}
No momento atual são 24 estados e o Distrito Federal, entre as 27 unidades federativas, com taxas iguais ou superiores a $80 \%$, sendo $15 \mathrm{com}$ taxas iguais ou superiores a $90 \%$. Em relação às capitais, 25 das 27 estão com taxas de ocupação de leitos de UTI COVID-19 para adultos iguais ou iguais superiores a 80\%, sendo 19 delas superiores a $90 \%$. [...] Um conjunto de indicadores, incluindo as médias móveis de casos e de óbitos e as taxas de ocupação de leitos UTI Covid-1 para adultos, apontam para situação extremamente crítica ou mesmo colapso, em todo o país. De modo urgente, é fundamental ampliar e intensificar conjunto de medidas não-farmacológicas, com medidas de supressão ou bloqueio da transmissão e do uso de máscaras de proteção, como principal medida de controle e redução do número de casos por COVID-19, buscando reverter ou evitar colapsos no sistema de saúde, para reduzir drasticamente os níveis de transmissão e de casos e, consequentemente, o número de mortes evitáveis (FUNDAÇÃO OSWALDO CRUZ, 2020, p. 1).
\end{abstract}

O nosso ponto de partida analítico é de que não há nada de inevitável ou natural nos números da COVID-19 no Brasil. Os números de contaminados e de mortes provocadas expressam diretamente o tratamento que o Estado tem dado a questão. O que se observa é a insistência da negação das orientações epidemiológicas - que apontaram uma segunda onda no país; e que afirmam que a única forma de conter o contágio, evitar mortes e de conter o colapso do sistema de saúde é o fechamento de atividades não essenciais. Dessa forma, o tratamento da pandemia no Brasil tem demonstrado, seguindo um fluxo histórico, de que nunca houve dúvidas entre o que é prioridade para a burguesia nacional, ou seja, a construção de um falso dilema entre economia versus saúde, onde a primeira é posta como prioridade. Não há dúvidas sobre o predomínio do interesse econômico do capital em 
detrimento da vida e saúde de trabalhadoras e trabalhadores e, especialmente, dos pobres e pretos/pretas.

Lembremo-nos que de acordo com dados da Pesquisa Nacional por Amostra de Domicílios Contínua 2019 (INSTITUTO BRASILEIRO DE GEOGRAFIA E ESTATÍSTICA, 2020), 42,7\% dos brasileiros se declararam como brancos, $46,8 \%$ como pardos, $9,4 \%$ como pretos e $1,1 \%$ como amarelos ou indígenas. Ou seja, atualmente cerca de $56,2 \%$ da população brasileira é negra, o somatório de pretos e pardos. Assim, a maioria da classe trabalhadora brasileira é formada por mulheres e homens negros.

É emblemático que em março de 2020 a primeira pessoa a morrer por COVID-19 no Brasil tenha sido uma mulher preta e trabalhadora doméstica, Dona Cleonice (UMA..., 2020). Ela tinha 63 anos e trabalhava, há 20 anos, como doméstica numa casa no bairro Leblon, Rio de Janeiro. Sua empregadora havia retornado recentemente de uma viagem à Itália. Cleonice era diabética e hipertensa e estava no trabalho quando começou a passar mal. Dois dias depois foi confirmado o óbito por COVID-19.

O estudo realizado pelo Núcleo de Operações e Inteligência em Saúde (NOIS) da PUC-Rio divulgado através da Nota Técnica n 11/2020 (BATISTA et al., 2020) e que teve como tema "Análise socioeconômica da taxa de letalidade da COVID-19 no Brasil" nos mostra que a COVID-19 não tem se comportado como em outros países. O estudo afirma que, no caso brasileiro, a progressão da doença sofre grande influência de fatores socioeconômicos e que pretos e pardos morrem mais de COVID-19 do que brancos. Tomando por base o elemento desigualdade de acesso ao tratamento, o estudo apontou que as chances de morte de um paciente preto ou pardo não alfabetizado são 3,8 vezes maiores do que de um paciente branco com nível superior.

Quando a pesquisa se volta apenas para a questão étnico-racial para avaliar os óbitos, os achados apontam que 55\% dos pretos e pardos faleceram; já entre os brancos, esse percentual foi de $38 \%$. Na avaliação por faixa etária, é visto que em todas as faixas os pacientes pretos e pardos apresentaram um número maior de óbitos em relação aos brancos.

Ao combinar as variáveis raça e escolaridade, os óbitos de pretos e pardos foram em maior proporção em todos os níveis de escolaridade se comparados aos brancos. Outra questão identificada foi de que as pessoas sem escolaridade tiveram taxas três vezes superiores (71,3\%) aos que têm nível superior (22,5\%). Desse modo, um dos achados da pesquisa foi que quanto maior a escolaridade, menor a letalidade da COVID-19.

A Organização Internacional do Trabalho (OIT), analisando os impactos da pandemia em 2020, apontou que foram perdidos cerca de 255 milhões de empregos em tempo integral. Esse número é aproximadamente quatro vezes superior ao número de empregos perdidos durante a crise financeira global de 2008-2009. A OIT estima ainda que 1,6 bilhão de trabalhadoras(es) na economia informal (quase a metade da força de trabalho global) correm o risco de não ter meios de subsistência (ILO, 2021).

No Brasil dados do Instituto Brasileiro de Geografia e Estatística (IBGE, 2021) obtidos através da Pesquisa Nacional por Amostra de Domicílios Contínua e divulgados em 2021 revelam que o desemprego, em 2020, atingiu 13,9 milhões de trabalhadoras e

Temporalis, Brasília (DF), ano 21, n. 41, p. 34-52, jan./jun. 2021. | ISSN 2238-1856 
trabalhadores, um recorde. Em 2019, a chamada população ocupada era de 93,4 milhões de pessoas no Brasil, no ano seguinte, este número caiu para 86,1 milhões de pessoas.

Referente aos meses de março e julho de 2020, a Oxfam Brasil (2020) apontou que o patrimônio dos 42 bilionários do Brasil cresceu com a pandemia, passando de US\$123,1 bilhões para US\$ 157,1 bilhões. A mesma tendência foi seguida em nível mundial, os 25 maiores bilionários do mundo aumentaram seu patrimônio em U\$ 255 bilhões nos primeiros três meses de pandemia em 2020, de acordo com estudo realizado pela Oxfam Internacional (2020). A Oxfam conclui que a fortuna dos bilionários do mundo contou, nos tempos iniciais da pandemia, com um incremento de 25\%, em relação ao ano de 2019.

Com a apresentação destes fatos e números relacionados à pandemia, nosso objetivo é dar sustentação à afirmação de que a COVID-19 não produziu uma crise econômica. O que ela fez foi intensificar os efeitos de uma crise já existente. Os excertos de Granemann e Miranda esclarecem essa processualidade.

\begin{abstract}
Notemos: as contradições que desde os anos 1990 engendraram crises econômicas que atingiram o coração do capitalismo mundial não foram resolvidas, mas jogadas para frente, em um movimento em que se 'compra tempo' ao preço de se aprofundarem os problemas e o potencial disruptivo do sistema econômico. A diferença é que desde a segunda década do século XXI a economia mundial não logrou uma recuperação minimamente sustentada, ao passo que o volume do capital fictício continuou crescendo a taxas espantosas. Nos últimos anos, recordemos, o apetite do capital pelos fundos públicos (inclusive na forma de programas de compras de ativos financeiros pelos governos), por novas privatizações, por contrarreformas que assegurassem a expansão do grau de exploração etc., só fez multiplicar-se, dada a crescente distância entre as condições de produção e apropriação do mais-valor no contexto da superacumulação de capital (GRANEMANN; MIRANDA, 2020, p. 25).
\end{abstract}

A pandemia afeta a todos, entretanto, o peso e os efeitos são vivenciados de formas distintas. Sob os ombros da classe trabalhadora recaem os maiores custos e não há nada de inevitável ou natural nesse processo, assim como não é algo novo. Os efeitos da crise sanitária causada pelo SARS-CoV-2 repercutem em meio a uma crise econômica vigente.

Considerando as afirmativas de Granemann e Miranda (2020) e pensando no contexto da pandemia, o que se observa é que a diligência do capital, das classes dominantes, não muda de forma no contexto pandêmico. O que acontece é a construção de estratégias para a obtenção de índices mais elevados de lucratividade, assim como de expansão de atividades mercantis em favor do lucro - não em favor da vida. Como já dito, a pandemia evidencia, de forma transparente, características estruturais do sistema capitalista, ou seja, explicita os processos de mercantilização da vida social em todas as suas dimensões.

Ao desenvolvimento do capitalismo são inerentes os ciclos de crise global (MANDEL, 1982) e suas expressões são identificadas nos campos social, econômico, político e também sanitário. Tais expressões comparecem desde os idos do século XIX. A constituição, o desenvolvimento e a expansão da sociedade capitalista significaram um alto grau de desenvolvimento das relações sociais, assim como significaram, também, vastos processos de exploração e alienação. 
Como apontado por Netto (1981), a sociedade burguesa alicerça uma forma própria de alienação, diferente de suas formas arcaicas, assumindo mecanismos concretos e particulares que não possibilitam compara-la a períodos históricos anteriores. Nas palavras de Netto, a sociabilidade capitalista opera "[...] abrigando e recolhendo as antigas formas de alienação repõe-nas em outro nível - justamente o engendrado pelo fetichismo" (NETTO, 1981, p. 71). Nesse processo, na esteira do pensamento marxiano, o próprio fundamento do capitalismo que é a mercantilização e a obtenção da mais-valia (ou do maisvalor).

E nesse processo estão incluídas as pessoas, as relações sociais e todas as demais coisas, destacando ainda que essa marcha permanece em desenvolvimento em tempos de pandemia. A reiteração de que a mercadoria é autônoma, obscurecendo seu caráter social, o trabalho de homens e mulheres, assim como obscurecendo a determinação social do adoecimento e morte por COVID-19.

Onze anos antes do surgimento do SARS-CoV-2, nos anos de 2008-2009, vivenciávamos os efeitos da redução da atividade econômica mundial e suas consequências sociais, especialmente para a classe trabalhadora. Os efeitos da pandemia não estão localizados exatamente na redução dos lucros do capital, mas sim na perda de renda dos trabalhadores e trabalhadoras.

A pandemia não provoca empatia no capitalista, o que ela faz é funcionar como um terreno para a acumulação e exploração da força de trabalho. É uma crise sanitária que engendra uma crise estrutural do capital. Antunes (2020), analisando o contexto da pandemia elucida:

A crise do coronavírus, a crise econômica e a interconexão profunda que há entre elas vêm impactando profundamente a classe trabalhadora. Desde logo, presenciamos um processo de ampliação do empobrecimento e dos níveis de miséria em amplas parcelas e segmentos dessa classe, cujo cotidiano é pautado ou por uma intensa exploração do trabalho e precarização ou, o que é ainda mais brutal, pelo flagelo do desemprego, subemprego e da informalidade, fenômenos explosivos e que têm uma dimensão global (ANTUNES, 2020, p. 180).

Fato é que a COVID-19 chega ao Brasil reforçando o terreno histórico ${ }^{3}$ da formação social brasileira. Na esteira das análises de Caio Prado Júnior e Florestan Fernandes, o desenvolvimento do capitalismo no Brasil se expressa sob a forma de dependência econômica, cultural e política do capitalismo central. A COVID-19 se expande no Brasil a partir dessa forma, dos contornos da particularidade brasileira.

Lembremo-nos que o Brasil se torna um Estado Nacional em 1822 quando a maioria dos trabalhadores brasileiros eram homens, mulheres e crianças escravizadas. Este é um país

\footnotetext{
3 Referindo-nos a tempos recentes, destacamos o progressivo desmonte dos recentes direitos sociais conquistados na Constituição Federal de 1988, resultado de lutas sociais e do processo de redemocratização. Como exemplos deste processo de desmonte, dentre outros, citamos a Emenda Constitucional n ${ }^{\circ}$ 95/2016 (a chamada Lei do Teto de Gastos) que além do congelamento dos gastos públicos por vinte anos, no que tange à saúde e à educação, há a desvinculação das despesas primárias; e a contrarreforma trabalhista de 2017, Lei $n^{\circ}$ 13.467/2017 (BRASIL, 2017), com esta legislação está posta a possibilidade de terceirização de todas as atividades, o que indica para os trabalhadores queda do nível salarial, perda de direitos sociais e estabilidade.
}

Temporalis, Brasília (DF), ano 21, n. 41, p. 34-52, jan./jun. 2021. | ISSN 2238-1856 
que se torna politicamente emancipado, tendo como base econômica o escravismo e o latifúndio (PRADO JÚNIOR, 1933; FERNANDES, 1976) e que carrega essa herança arcaica e conservadora ao longo de sua história. E como apontou Fernandes, a burguesia brasileira não forjou "[...] instituições próprias de poder especialmente social [...]" (FERNANDES, 1976, p. 204), utilizou o Estado como meio para o exercício de dominação. A mesma forma é utilizada no contexto pandêmico quando o Estado - com o objetivo de diminuir os impactos econômicos que foram causados pela pandemia - comparece para os trabalhadores e trabalhadoras informais ou de baixa renda, microempreendedores individuais e contribuintes individuais do Instituto Nacional do Seguro Social (INSS), na forma de pífio Auxílio Emergencial.

Instituído no país pela Lei $n^{\circ}$ 13.982/2020 (BRASIL, 2020a), o Auxílio Emergencial indicava o repasse de $\mathrm{R} \$ \mathbf{6 0 0 , 0 0}$ reais mensais, em princípio, destinados em três parcelas. Em setembro de 2020, o governo federal anunciou o pagamento de mais quatro parcelas de $\mathrm{R} \$ 300,00$ reais, ainda no exercício de 2020. Em 2021, havendo indicações científicas desde novembro de 2020 de que haveria uma segunda onda da COVID-19 nos primeiros meses de 2021, foi aprovado, através da Medida Provisória n 1039/2021 (BRASIL, 2021), o Auxílio Emergencial 2021 no valor de $\mathrm{R} \$ 250,00$ reais. Além da contínua diminuição do valor, 0 Auxílio 2021 só pode ser acessado por trabalhadores que se inscreveram no auxílio em 2020 e a esta regra que já é excludente são somados ainda outros novos critérios de elegibilidade que em seu conjunto significam limites de acesso.

Na construção histórica brasileira a burguesia orientou e controlou o poder político estatal de forma a atender seus interesses. A subordinada burguesia brasileira reforçava (e reforça) seus vínculos externos de dependência e os internos de dominação - fato observado também na chegada do SARS-CoV-2. Do ponto de vista interno, na mesma medida em que se autoprivilegia, impossibilita tanto o desenvolvimento econômico com base no que poderia ser identificado como interesse nacional - especialmente se localizarmos o contexto pandêmico - quanto a construção de alicerces para uma lógica de universalização de direitos sociais no Brasil.

Encerramos esta sessão com uma síntese que nos parece abarcar a lógica que nos trouxe até aqui, recorrendo à análise de Marx sobre o processo global da produção capitalista, passagem presente no livro III de O Capital. Sobre as crises, Marx asseverou: “[...] são sempre apenas violentas soluções momentâneas das contradições existentes, erupções violentas que restabelecem por um momento o equilíbrio perturbado" (MARX, 2017, p. 289).

\section{EXERCÍCIO PROFISSIONAL EM SERVIÇO SOCIAL NA SAÚDE: ALGUMAS IMPLICAÇÕES DO CONTEXTO PANDÊMICO}

A pandemia do novo coronavírus avança no país em uma conjuntura de inúmeros retrocessos na sociedade brasileira e na política de saúde. Em 2019, o governo Bolsonaro já investia nas estratégias de precarização das relações de trabalho e empregatícias, no ataque aos direitos sociais, na disseminação de valores antidemocráticos e na consolidação de uma extrema direita, defensora de um projeto claramente privatista para a seguridade social. É nesse contexto já posto de precarização e desconstrução de direitos que vivenciamos a pandemia, como esclarecem Castilho e Lemos (2021), 
No Brasil, a aceleração das políticas ultraconservadoras e ultraneoliberais encontraram, no governo de Jair Bolsonaro, um solo fértil para crescer e se alastrar sem medidas. Os sucessivos cortes e privatização na saúde pública, na previdência e assistência social fazem a diferença nas ações do Estado para conter ou não a pandemia em terras brasileiras (CASTILHO; LEMOS, 2021, p. 271).

Pensando do ponto de vista histórico-crítico, desde sua origem, a classe trabalhadora brasileira foi pautada pela precarização (ANTUNES, 2018). No contexto pré-pandemia, comparada aos países de capitalismo central, sua característica histórica e atual é a combinação de intensidade da exploração do trabalho, ou seja, o aumento da mais-valia absoluta com longas jornadas de trabalho e com ritmo intenso; e baixa remuneração, abaixo das necessidades mínimas para a sobrevivência. No curso da pandemia, o que se vê é o acirramento do conflito dos distintos interesses de classe.

A saúde expressa também as contradições da luta de classes, revelando os interesses antagônicos presentes na relação capital e trabalho que incidem diretamente nas formas de propagação do vírus e nas possibilidades de prevenção, acesso ao tratamento, cura e reabilitação da doença. Ou seja, o processo saúde-doença se realiza em interface com as expressões da questão social, evidenciando as desigualdades sociais.

Dessa forma, o exercício profissional desenvolvido por assistentes sociais na saúde no contexto da pandemia não pode ter outro ponto de partida senão a determinação social do processo saúde-doença, que, como apontado por Souza (2020), apreende o caráter dialético, que pressupõe a indissociabilidade dos aspectos biológicos, sociais, culturais e políticos presentes na saúde individual e/ou coletiva, entrelaçando com as relações socialmente construídas, particularmente as relações sociais de produção.

Se o objetivo da profissão na área da saúde passa pela compreensão da determinação social, econômica e cultural que interfere no processo saúde-doença e na busca de estratégias político-institucionais que possam enfrentar essas questões, conforme já indicado por Bravo e Matos (2004) e pelo CFESS (2010); e se é sabido que o objeto da nossa intervenção profissional consiste nas manifestações da questão social, não é possível desconsiderar a determinação social do processo saúde-doença na análise do exercício profissional no campo da saúde, especialmente em tempos de pandemia.

É assim que a pandemia publiciza para o mundo a histórica desigualdade posta pela sociedade capitalista que, no caso do Brasil, é intensificada pela crise da saúde pública, marcada pela incompleta implementação do SUS. Ao possuir fundamentos teóricos e princípios políticos que sustentam a resistência dos sujeitos sociais a ele adeptos e ao mesmo tempo em que é alvo de disputa, o SUS também tensiona o capital, provocando-o a recuar, ao menos em algumas frentes e em momentos que ele pretendia se espraiar ainda mais.

Reflexo disso é o aumento da precarização do trabalho e do desemprego, já decorrentes da incorporação de novas tecnologias e da nova organização da produção bem como da destruição dos direitos do trabalho (TONET, 2009). Nesse contexto, o aprofundamento dessas desigualdades trouxe à tona a realidade da população brasileira que se caracteriza pela ausência de moradia e pelo inexistente ou precário abastecimento de água e saneamento básico - realidade que se contradiz frente às recomendações de isolamento doméstico e de prevenção. Não à toa escuta-se que a pandemia escancarou o colocado

Temporalis, Brasília (DF), ano 21, n. 41, p. 34-52, jan./jun. 2021. | ISSN 2238-1856 
como invisível. E é nessa realidade que vive a classe trabalhadora e onde atuam as(os) assistentes sociais.

Além disso, os trabalhadores da saúde lidam, cotidianamente, com o medo, a tensão e a insegurança gerados pela pandemia e agravados pela já sabida incapacidade dos serviços de saúde, como também apontado por Matos (2020), e que hoje é potencializada pela falta de leitos e de equipamentos fundamentais no tratamento da COVID-19 - como os respiradores, na assistência à saúde - e os Equipamentos de Proteção Individual (EPIs). Fazse, então, importante tomar a razão emancipatória como meio para enfrentar esse medo, reafirma o próprio autor, o que significa a necessidade de apropriação do conhecimento dessa realidade epidemiológica e do processo de adoecimento.

Esse contexto impacta diretamente o Serviço Social, seja na organização dos serviços e das atribuições e competências de assistentes sociais nos diferentes espaços sócioocupacionais, com destaque para o SUS, seja nas condições de vida, saúde e trabalho da população atendida cada vez mais subalternizada e destituída dos seus direitos.

Conforme salienta Raichelis e Arregui (2021), a pandemia atinge o cerne das atribuições e competências profissionais levando a categoria a enfrentar, nos mais distintos espaços de trabalho, significativas pressões político-institucionais.

\begin{abstract}
Os variados estudos, levantamentos, depoimentos, bem como o acompanhamento atento do debate profissional em diversos espaços ocupacionais, públicos e privados, evidenciam, de um lado, o medo, as pressões, as angústias reais de assistentes sociais, especial, mas não exclusivamente, daqueles(as) que estão na linha de frente do trabalho presencial; e de outro, os sofrimentos e adoecimentos desencadeados em todos(as), tanto no trabalho presencial quanto no remoto, em meio à impotência para fazer frente às expressões mais dramáticas da questão social e às necessidades urgentes dos indivíduos e famílias que demandam atenção pública (RAICHELIS; ARREGUI, 2021, p. 144).
\end{abstract}

No entanto, como nos afirma Matos (2020), apesar das alterações na forma de desenvolvimento do trabalho e dos tensionamentos trazidos pela pandemia, as atribuições privativas e competências profissionais devem ser mantidas e preservadas, sendo desenvolvidas e balizadas nas normativas da profissão estabelecidas pelo Código de Ética $\mathrm{da}(\mathrm{o})$ Assistente Social e Lei de Regulamentação da Profissão, bem como nas Resoluções do CFESS e nos Parâmetros para Atuação de Assistentes Sociais na Política de Saúde (CONSELHO FEDERAL DE SERVIÇO SOCIAL, 2010).

As características da pandemia da COVID-19 reacenderam na profissão discussões já realizadas e contempladas nos Parâmetros (CONSELHO FEDERAL DE SERVIÇO SOCIAL, 2010). Uma delas é a alta letalidade causada pela COVID-19 que situa a sociedade frente às inúmeras situações de óbitos, provocando a categoria a enfrentar o debate sobre a comunicação de óbito (e convocação da família para informar sobre alta e óbito), o que é considerado como não atribuição profissional de assistentes sociais (CONSELHO FEDERAL DE SERVIÇO SOCIAL, 2010; 2020b). Frente ao que fez parecer desconhecimento das competências das(dos) assistentes sociais ou uma compreensão conservadora da função social da profissão, o Ministério da Saúde recomendou logo no início da pandemia que “[...] 
a comunicação do óbito seja realizada aos familiares, amigos e responsáveis, preferencialmente, por equipes da atenção psicossocial e/ou assistência social" (BRASIL, 2020b, p. 6).

Nessa mesma lógica, e também em face das precarizadas condições de trabalho, gestores e equipes de saúde passaram a requisitar às(aos) assistentes sociais a divulgação de boletins de saúde (que contêm informações clínicas das pessoas internadas, que envolvem o tratamento proposto, a evolução da doença e seus prognósticos ${ }^{4}$ ) e a participação em triagens das condições clínicas de usuários e usuárias com suspeitas de COVID-19 para o acesso aos serviços de saúde. No entanto, ao considerarmos que a atestação tanto das condições de saúde, doenças e possíveis sequelas bem como do óbito são atividades privativas do médico (BRASIL, 2013, art. $4^{\circ}$, incisos XIII e XIV) e que o ato de atestar significa comprovar algo de maneira oficial e por escrito, pressupõe que tais ações foram precedidas por avaliação técnica realizada pela equipe médica, entendemos que a comunicação de toda informação clínica dessa avaliação derivada deve ser competência da mesma equipe profissional que a produziu, o que não inviabiliza a assistência às famílias dada por assistentes sociais.

Essa realidade nos faz retomar a análise realizada por Costa, há quinze anos, acerca da inserção das(dos) assistentes sociais nos serviços de saúde, na qual indicava que as condições de funcionamento do SUS e o modo pelo qual os serviços são produzidos estão na base de sustentação das demandas então colocadas às(aos) assistentes sociais, cujas ações estão voltadas a suprir as lacunas geradas pelos demais profissionais que participam do trabalho em saúde (COSTA, 2006). Parece-nos que o contexto pandêmico repõe esta discussão e seus desafios ético-profissionais.

Apesar dos desafios, podemos indicar que, nesse intervalo de mais de quinze meses de pandemia no Brasil, a profissão construiu estratégias que potencializam o atendimento à população.

Na atenção primária, por exemplo, destaca-se o trabalho profissional voltado para as ações de promoção e prevenção da saúde nos territórios, dando continuidade ao cuidado em saúde; com a difusão de orientações sobre a pandemia e demais necessidades de saúde da população; e acompanhamento dos grupos mais expostos devido à comorbidades. Esse movimento é fundamental para combater a lógica de responsabilização individual pelo cuidado e proteção contra o vírus, buscando superar a perspectiva de culpabilização dos indivíduos por suas condições de vida e trabalho. Desta forma, em articulação com a equipe de saúde, permanece sendo essencial reforçar os princípios históricos da atenção primária e suas ações de vigilância sanitária e epidemiológica nos territórios, de cuidados domiciliares e de monitoramento e avaliação dos problemas de saúde da população (FACCHINI, 2020).

\footnotetext{
${ }^{4}$ Cabe dizer que, de acordo com o Código de Ética Médica, constitui-se como uma proibição “[...] deixar de esclarecer o paciente sobre as determinantes sociais, ambientais ou profissionais de sua doença [...]" (CONSELHO FEDERAL DE MEDICINA, 2019, p. 22, art. 13), bem como "[...] deixar de informar ao paciente o diagnóstico, o prognóstico, os riscos e os objetivos do tratamento, salvo quando a comunicação direta possa Ihe provocar dano, devendo, nesse caso, fazer a comunicação a seu representante legal" (CONSELHO FEDERAL DE MEDICINA, 2019, p. 27, art. 34).
}

Temporalis, Brasília (DF), ano 21, n. 41, p. 34-52, jan./jun. 2021. | ISSN 2238-1856 
Nos hospitais, a participação do Serviço Social no processo de construção de fluxos de admissão e alta de usuários e usuárias é um imperativo. No processo de admissão é preciso garantir a identificação do familiar ou contato de referência já que, muitas vezes, essas pessoas chegam às unidades hospitalares conduzidas por equipe de transporte sanitário e sem acompanhante. Já na discussão sobre a possibilidade de alta, é fundamental verificar as condições para a manutenção do isolamento doméstico, o grau de compreensão da população usuária e sua família sobre a COVID-19 e a realização do seu monitoramento no território, o que exige a interlocução com a rede de serviços de saúde, especialmente, com a Unidade Básica de Saúde de referência.

Nesse sentido, observa-se o reforço das ações socioassistenciais realizadas pela(o) assistente social potencializadas pela busca pela democratização das informações por meio de orientações e/ou encaminhamentos quanto aos direitos sociais da população usuária, bem como a construção da abordagem socioeducativa com os usuários, as usuárias e suas famílias que visem a compreensão do processo saúde-doença (CONSELHO FEDERAL DE SERVIÇO SOCIAL, 2010). Torna-se fundamental também a democratização das rotinas e o funcionamento das unidades de saúde (CONSELHO FEDERAL DE SERVIÇO SOCIAL, 2012) assim como o diálogo com a gestão dos serviços, com vistas a assegurar a qualidade das informações ofertadas à população neste contexto.

Concebido como um direito humano, o direito à informação ganha importância ainda maior no contexto da pandemia da COVID-19, à medida que o conhecimento que a população usuária e/ou a sua família possui tanto do seu estado de saúde como dos dados epidemiológicos, de prevenção e controle dos agravos em saúde - comunicado de acordo com suas necessidades e realidade - pode determinar as ações de cuidado de todas as pessoas que com ele vivem (TANURE; MELGAÇO; ALBUQUERQUE, 2020). A dificuldade em ter esse direito assegurado está associada à incapacidade dos serviços de compreender os usuários, as usuárias e seus familiares como sujeitos de direitos, cuja autonomia deve ser resguardada, e de superar as relações de poder historicamente hierarquizadas, estabelecendo vínculos capazes de construir relações de igualdade entre a população usuária e trabalhadores e trabalhadoras da saúde.

A reafirmação do conjunto dos direitos de usuários e usuárias é essencial, pois, como destacado por Albuquerque (2020, p. 6-7), “[...] a COVID-19 é uma crise também de direitos humanos, na medida em que seu enfrentamento impõe uma batalha pelo direito à vida e pelo direito à saúde de todas as pessoas, bem como a atenção especial ao direito de populações vulneráveis de não serem discriminadas [...]", por isso, o trabalho das(dos) assistentes sociais durante essa pandemia deve ser conduzido pelos princípios éticos da profissão.

Merecem destaque, nesse debate, os elementos que dizem respeito às condições técnicas e éticas de trabalho de assistentes sociais na saúde. Conforme Soares, Correia e Santos (2021), a categoria tem se deparado com relações de trabalho precarizadas, demonstradas pela inserção nos serviços de saúde por meio de contratos temporários, inseguros e com baixa remuneração. Agrega-se a essa realidade, condições de trabalho também precárias, caracterizadas pela ausência de infraestrutura adequada para a acomodação das equipes, realização dos atendimentos e desenvolvimento das ações profissionais cotidianas que, aliadas à necessária diminuição do fluxo de pessoas, têm levado muitos serviços de saúde

Temporalis, Brasília (DF), ano 21, n. 41, p. 34-52, jan./jun. 2021. | ISSN 2238-1856 
a utilizar como estratégia a plantonização da jornada de trabalho (SOARES; CORREIA; SANTOS, 2021). Entendemos que é necessária a problematização deste processo, uma vez que esta lógica pode recair no recebimento passivo de demandas e se desdobrar em ações imediatas, isoladas, que reduzem o campo de atuação profissional, como aponta Vasconcelos (2006).

Ressaltamos também o crescente volume e a complexidade das demandas apresentadas pelas famílias da população usuária e pelas equipes de saúde - que requer a garantia do local de atendimento adequado, o respeito à distância segura e à ventilação adequada do ambiente. As normatizações e recomendações do Conselho Federal de Serviço Social (CFESS) e dos Conselhos Regionais do país constituíram-se como importantes referências para diálogo com a população, em que pese o direito ao sigilo profissional. Ressaltamos, nesse caso, a Resolução CFESS nº 493/2006.

Outro elemento é a incorporação do teleatendimento como uma ação estratégica no acesso aos usuários, às usuárias e seus familiares, através de orientações socioeducativas e de socialização de informações à população, com destaque para a dinâmica de funcionamento dos serviços. No entanto, é necessário identificar os limites dessa estratégia para a construção de estudos sociais e levantamentos de dados sobre a realidade social e familiar, além de ter atenção aos cuidados éticos e à informação técnica a ser elaborada e compartilhada, como sinalizado por CFESS (2020a).

Nesse cenário de alterações e tensões que a pandemia traz, finalizando a sessão, ressaltamos o que Matos (2015) sinaliza sobre o debate das atribuições e competências profissionais:

A profissão de Serviço Social está em movimento, como tudo que tem e faz história. Nesse movimento - que é real e independente da vontade dos sujeitos envolvidos -, temos o desafio coletivo de empreendermos respostas às demandas que nos são solicitadas e que consideramos pertinentes, bem como também precisamos sempre apurar nosso discernimento sobre as requisições enviesadas que são dirigidas à profissão (MATOS, 2015, p. 696).

\section{CONSIDERAÇÕE FINAIS}

Neste ensaio buscamos explicitar que a crise sanitária da COVID-19 reforçou uma crise econômica que já estava em curso, reafirmando as crises cíclica do capitalismo (MANDEL, 1982). Destacamos também que as respostas a estas crises são o recrudescimento das condições sociais de reprodução de trabalhadores e trabalhadoras. A pandemia deixou desnudas as desigualdades próprias do modo de produção capitalista. E no Brasil a COVID19 avança em uma conjuntura sócio-histórica de inúmeros retrocessos dos direitos sociais.

No que se refere ao exercício profissional na pandemia, ressaltamos a combinação de novas e revisitadas demandas postas ao Serviço Social. E, nesse sentido, reiteramos que a contribuição das(os) assistentes sociais da saúde no contexto da pandemia do COVID-19 deve realizar-se no campo das suas competências profissionais e de suas atribuições privativas, assentada nas normativas da profissão e nos Parâmetros para Atuação de Assistentes Sociais na Política de Saúde (CONSELHO FEDERAL DE SERVIÇO SOCIAL, 2010). 
Por fim, indicamos que o debate acerca do exercício profissional na pandemia não pode se afastar das lutas mais amplas da categoria e da organização geral dos trabalhadores e trabalhadoras, daí a necessidade de aproximação e participação nos movimentos contrahegemônicos na saúde, como a Frente Nacional Contra a Privatização da Saúde, assim como os fóruns regionais a ela vinculados. Isso porque esse contexto nos impõe a defesa do projeto ético-político profissional, mas também das bandeiras da Reforma Sanitária dos anos 1980, que hoje passa pela defesa do SUS e seus trabalhadores, da democracia e, fundamentalmente, pela defesa da vida acima do lucro.

\section{REFERÊNCIAS}

ALBUQUERQUE, A. A pandemia da COVID-19 sob o enfoque de direitos humanos. In: ALBUQUERQUE, A.; ELER, K. (Coord.) Direitos humanos dos pacientes e COVID-19. Brasília (DF): Observatório dos Direitos dos Pacientes / PPoGB-UnB; UFJF; UNESCO, abr. 2020, p. 5-8. Disponível em: http://www.observatoriopaciente.com.br/wpcontent/uploads/2020/05/direitos_humanos_pacientes_covid_impressao.pdf. Acesso em: 3 jun. 2020.

ANTUNES, R. O vilipêndio do coronavírus e o imperativo de reinventar o mundo. In: TOSTES, A.; MELO FILHO, H. (Org.) Quarentena: reflexões sobre a pandemia e depois [recurso digital]. 1.ed. Bauru: Canal 6, 2020, p. 181-188. Disponível em:

http://editorapraxis.com.br/quarentena/ebook_quarentena_1ed_2020.pdf. Acesso em: 21 mar. 2021.

ANTUNES, R. O privilégio da servidão [recurso eletrônico]: o novo proletariado de serviços na era digital. 1.ed. São Paulo: Boitempo, 2018.

BARRETO, M. L. et al. O que é urgente e necessário para subsidiar as políticas de enfrentamento da pandemia de COVID-19 no Brasil? Rev. bras. epidemiol., Rio de Janeiro, v. 23, e200032, 2020. Disponível em: https://www.scielo.br/pdf/rbepid/v23/1980-5497rbepid-23-e200032.pdf. Acesso em: 19 dez. 2020.

BATISTA, A. et al. Análise socioeconômica da taxa de letalidade da COVID-19 no Brasil. Rio de Janeiro: Núcleo de Operações e Inteligência em Saúde (NOIS), 27 maio 2020. (Nota Técnica, n. 11). Disponível em:

https://drive.google.com/file/d/1tSU7mV4OPnLRFMMY47JIXZgzkklvkydO/view. Acesso em: 5 jun. 2020.

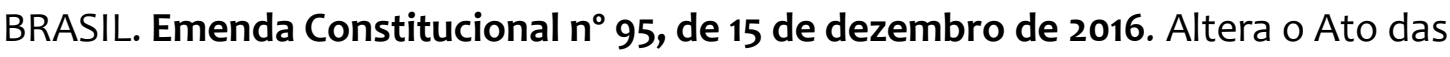
Disposições Constitucionais Transitórias, para instituir o Novo Regime Fiscal, e dá outras providências. Brasília (DF), 2016. Disponível em:

http://www.planalto.gov.br/ccivil_03/constituicao/emendas/emc/emc95.htm. Acesso em: 19 dez. 2020.

BRASIL. Medida Provisória $n^{\circ}$ 1.039, de 18 de março de 2021. Institui o Auxílio Emergencial 2021 para o enfrentamento da emergência de saúde pública de importância internacional decorrente do coronavírus (COVID-19). Brasília (DF), 2021. Disponível em: 
http://www.planalto.gov.br/ccivil_03/_Ato2019-2022/2021/Mpv/mpv1039.htm. Acesso em: 21 mar. 2020.

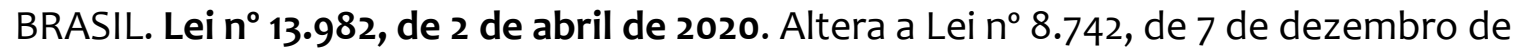
1993, para dispor sobre parâmetros adicionais de caracterização da situação de vulnerabilidade social para fins de elegibilidade ao benefício de prestação continuada (BPC), e estabelece medidas excepcionais de proteção social a serem adotadas durante o período de enfrentamento da emergência de saúde pública de importância internacional decorrente do coronavírus (COVID-19) responsável pelo surto de 2019, a que se refere a Lei $\mathrm{n}^{\circ}$ 13.979, de 6 de fevereiro de 2020. Brasília (DF), 2020a. Disponível em: http://www.planalto.gov.br/ccivil_03/_ato2019-2022/2020/lei/l13982.htm. Acesso em: 19 dez. 2020.

BRASIL. Lei $\mathbf{n}^{\circ} \mathbf{1 2 . 8 4 2}$, de 10 de julho de 2013. Dispõe sobre o exercício da Medicina. Brasília (DF), 2013. Disponível em: http://www.planalto.gov.br/ccivil_03/_Ato20112014/2013/Lei/L12842.htm\#: :text=Art.,sem\%20discrimina\%C3\%A7\%C3\%A30\%20de\%20qualqu er\%2onatureza. Acesso em: 6 jun. 2020.

BRASIL. Lei $\mathbf{n}^{\circ} \mathbf{1 3 . 4 6 7}$, de 13 de julho de 2017. Altera a Consolidação das Leis do Trabalho $(C L T)$, aprovada pelo Decreto-Lei $n^{\circ} 5.452$, de $1^{\circ}$ de maio de 1943 , e as Leis $n^{\circ} 6.019$, de 3 de janeiro de 1974, 8.036, de 11 de maio de 1990, e 8.212, de 24 de julho de 1991, a fim de adequar a legislação às novas relações de trabalho. Brasília (DF), 2017. Disponível em: http://www.planalto.gov.br/ccivil_03/_ato2015-2018/2017/lei/l13467.htm. Acesso em: 19 dez. 2020.

BRASIL. Lei $\mathbf{n}^{\circ} \mathbf{8 . 0 8 0}$, de 19 de setembro de 1990. Dispõe sobre as condições para a promoção, proteção e recuperação da saúde, a organização e o funcionamento dos serviços correspondentes e dá outras providências. Disponível em:

http://www.planalto.gov.br/ccivil_03/leis//8080.htm. Acesso em: 02 jun. 2020.

BRASIL. Ministério da Saúde. Secretaria de Vigilância em Saúde. Departamento de Análise em Saúde e Vigilância de Doenças não Transmissíveis. Manejo de corpos no contexto do novo coronavírus COVID-19. Brasília (DF): Ministério da Saúde, 2020b. Disponível em: https://portalarquivos.saude.gov.br/images/pdf/2020/marco/25/manejo-corposcoronavirus-versa01-25mar20-rev5.pdf . Acesso em: 21 maio 2020.

BRAVO, M. I. S.; MATOS, M. C. Reforma Sanitária e Projeto ético-político do Serviço Social: elementos para o debate. In: BRAVO, M. I. S. et al. (Org.) Saúde e Serviço Social. São Paulo: Cortez; Rio de Janeiro: UERJ, 2004, p. 25-47.

CASTILHO, D. R.; LEMOS, E. L. S. Necropolítica e governo Jair Bolsonaro: repercussões na seguridade social brasileira. R. Katálysis. Florianópolis, v.24, n. 2, p. 269-279, 2021. Disponível em: https://periodicos.ufsc.br/index.php/katalysis/article/view/75361. Acesso em: 13 junho 2021.

CONSELHO FEDERAL DE MEDICINA (CFM). Código de Ética Médica: Resolução CFM n ${ }^{\circ}$ 2.217, de 27 de setembro de 2018, modificada pelas Resoluções CFM n 2.222/2018 e 2.226/2019. Brasília (DF): CFM, 2019. Disponível em: https://portal.cfm.org.br/images/PDF/cem2019.pdf. Acesso em: 6 jun. 2020.

Temporalis, Brasília (DF), ano 21, n. 41, p. 34-52, jan./jun. 2021. | ISSN 2238-1856 


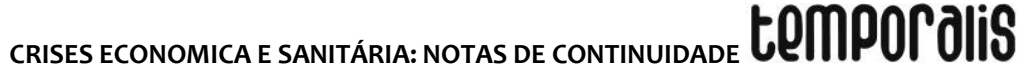

CONSELHO FEDERAL DE SERVIÇO SOCIAL (CFESS). Código de ética do/a assistente social e Lei 8.662/93 de regulamentação da profissão. 10.ed. revista e atualizada. Brasília: CFESS, 2012. Disponível em: http://www.cfess.org.br/arquivos/CEP_CFESS-SITE.pdf. Acesso em: 22 março 2021.

CONSELHO FEDERAL DE SERVIÇO SOCIAL (CFESS). Parâmetros de atuação de assistentes sociais na política de saúde. Brasília: CFESS, 2010. Disponível em:

http://www.cfess.org.br/arquivos/Parametros_para_a_Atuacao_de_Assistentes_Sociais na_Saude.pdf. Acesso em: 22 março 2021.

CONSELHO FEDERAL DE SERVIÇO SOCIAL (CFESS). Orientação Normativa $\mathbf{n}^{\circ} \mathbf{3}$, de $\mathbf{3 1}$ de março de 2020b. Dispõe sobre ações de comunicação de boletins de saúde e óbitos por assistentes sociais. Disponível em:

http://www.cfess.org.br/arquivos/OrientacaoNormat32020.pdf. Acesso em: 22 maio 2020.

CONSELHO FEDERAL DE SERVIÇO SOCIAL (CFESS). Resolução $\mathbf{n}^{\circ}$ 493, de 21 de agosto de 2006. Ementa: Dispõe sobre as condições éticas e técnicas do exercício profissional do assistente social. Disponível em: http://www.cfess.org.br/arquivos/Resolucao_493-06.pdf. Acesso em: 22 maio 2020.

CONSELHO FEDERAL DE SERVIÇO SOCIAL (CFESS). Teletrabalho e Teleperícia: orientações para assistentes sociais no contexto da pandemia. 2020a. Disponível em: http://www.cfess.org.br/arquivos/Nota-teletrabalho-telepericiacfess.pdf. Acesso em: 18 set. 2020.

COSTA, M. D. H. O trabalho nos serviços de saúde e a inserção dos(as) assistentes sociais. In: MOTA, A. E et al. (Org). Serviço Social e Saúde: Formação e trabalho profissional. São Paulo: Cortez, 2006, p. 304-351.

FACCHINI, L. A. COVID-19: Nocaute do neoliberalismo? Será possível fortalecer os princípios históricos do SUS e da APS em meio à pandemia? APS em Revista, Belo Horizonte (MG), v. 2, n. 1, p. 3-10, jan./abr., 2020. Disponível em:

https://apsemrevista.org/aps. Acesso em: 02 jun. 2020.

FERNANDES, F. A revolução burguesa no Brasil: ensaio de interpretação sociológica. Rio de Janeiro: Zahar, 1976.

FUNDAÇÃO OSVALDO CRUZ (FIOCRUZ). Observatório COVID-19. Boletim Extraordinário do Observatório COVID-19, Rio de Janeiro, 16 mar. 2021. Disponível em:

https://portal.fiocruz.br/sites/portal.fiocruz.br/files/documentos/boletim_extraordinario 2021-marco-16-red-red-red.pdf. Acesso em: 20 mar. 2021.

GARCIA, L. P.; DUARTE, E. Intervenções não farmacológicas para o enfrentamento à epidemia da COVID-19 no Brasil. Epidemiol. Serv. Saúde, Brasília (DF), v. 29, n. 2, e2020222, 2020. Disponível em: http://scielo.iec.gov.br/pdf/ess/v29n2/2237-9622-ess-29-02e2020222.pdf. Acesso em: 02 jun. 2020. 
GRANEMANN, S.; MIRANDA, F. Crise econômica, crise sanitária: a COVID-19 como instrumento da acumulação? In: SILVA, L. B.; DANTAS, A. V. (Org.) Crise e pandemia: quando a exceção é regra geral. Rio de Janeiro: EPSJV/FIOCRUZ, 2020. Disponível em: http://www.epsjv.fiocruz.br/sites/default/files/crise_e pandemia.pdf. Acesso em: 10 mar. 2021.

GUIMARÃES, R. Vacinas anticovid: um olhar da Saúde Coletiva. Ciênc. saúde coletiva, Rio de Janeiro, v. 25, n. 9, p. 3579-3585, 2020. Disponível em:

https://www.scielo.br/pdf/csc/v25n9/1413-8123-csc-25-09-3579.pdf. Acesso em: 10 mar. 2021.

HARVEY, D. A condição pós-moderna. São Paulo: Loyola, 2002.

ILO. ILO Monitor: COVID-19 and the world of work. Seventh edition. Updated estimates and analysis, 2021. Disponível em: https://www.ilo.org/wcmsp5/groups/public/--dgreports/---dcomm/documents/briefingnote/wcms_767028.pdf. Acesso em: 10 mar. 2021.

INSTITUTO BRASILEIRO DE GEOGRAFIA E ESTATÍSTICA (IBGE). Indicadores IBGE: Pesquisa Nacional por Amostra de Domicílios Contínua: Quarto Trimestre de 2020. Brasília (DF), 2021. Disponível em: https://biblioteca.ibge.gov.br/visualizacao/periodicos/2421/pnact_2020_4tri.pdf. Acesso em: 20 mar. 2021.

INSTITUTO BRASILEIRO DE GEOGRAFIA E ESTATÍSTICA (IBGE). Informativo PNAD Contínua 2019: Características gerais dos domicílios e dos moradores 2019. Brasília (DF), 2020. Disponível em:

https://biblioteca.ibge.gov.br/visualizacao/livros/liv101707 informativo.pdf. Acesso em: 20 jun. 2020.

MANDEL, E. O capitalismo tardio. Col. Os economistas. São Paulo: Abril Cultural, 1982.

MARX, K. O Capital: crítica da economia política: o processo global da produção capitalista: livro III. São Paulo: Boitempo, 2017.

MATOS, M. C. A Pandemia da COVID-19 e o trabalho de assistentes sociais na saúde. In: LOLE, A.; STAMPA, I.; GOMES, R. L. R. (Org.). Para além da quarentena: Reflexões sobre crise e pandemia. Rio de Janeiro: Mórula Editorial, 2020, p. 237-249. Disponível em: https://morula.com.br/wp-content/uploads/2020/06/ParaAlemDaQuarentena.pdf. Acesso em: 16 jul. 2020.

MATOS, M. C. Considerações sobre atribuições e competências profissionais de assistentes sociais na atualidade. Serv. Soc. Soc., São Paulo, n. 124, p. 678-698, out./dez. 2015. Disponível em:

https://www.scielo.br/j/sssoc/a/zKqHPXTYyTSPvMBrGZnzgjm/?lang=pt Acesso em:10 jun. 2021.

MÉSZÁROS, I. Para além do capital: rumo a uma teoria da transição. São Paulo: Boitempo, 2002. 


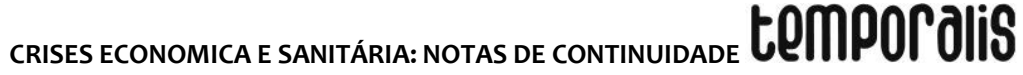

NETTO, J. P. Capitalismo e reificação. São Paulo: Ciências Humanas, 1981.

OUR WORLD IN DATA. Coronavirus Pandemic COVID-19. Coronavirus (COVID-19)

Vaccinations. 2021. Disponível em: https://ourworldindata.org/coronavirus. Acesso em: 20 mar. 2021.

OXFAM BRASIL. Bilionários da América Latina aumentaram fortuna em US\$ 48,2 bilhões durante a pandemia. 2020. Disponível em: https://www.oxfam.org.br/noticias/bilionariosda-america-latina-e-do-caribe-aumentaram-fortuna-em-us-482-bilhoes-durante-a-

pandemia-enquanto-maioria-da-populacao-perdeu-emprego-e-renda/. Acesso em: 15 mar. 2021.

OXFAM INTERNACIONAL. Poder, lucros e a pandemia: Da distribuição excessiva de lucros e dividendos de empresas para poucos para uma economia que funcione para todos.

Nota Informativa da Oxfam, set. 2020. Disponível em:

https://d335luupugsy2.cloudfront.net/cms\%2Ffiles\%2F115321\%2F1599751979Poder_Lucros e_a_Pandemia__completo_editado__pt-BR.pdf. Acesso em: 15 mar. 2021

PRADO JÚNIOR, C. Evolução política do Brasil: colônia e império. São Paulo: Brasiliense, 1933.

RAICHELIS, R; ARREGUI, C. C. O trabalho no fio da navalha: nova morfologia no Serviço Social em tempos de devastação e pandemia. Serv. Soc. Soc., São Paulo, n. 140, p. 134-152, jan./abr. 2021. Disponível em:

https://www.scielo.br/j/sssoc/a/MVGcWc6sHCP9wFM5GHrpwQR/?lang=pt\&format=pdf

Acesso em: 9 jun. 2021.

SOARES, R. C.; CORREIA, M. V. C.; SANTOS, V. M. Serviço Social na política de saúde no enfrentamento da pandemia da COVID-19. Serv. Soc. Soc., São Paulo, n. 140, p. 118-133, jan./abr. 2021. Disponível em: https://www.scielo.br/pdf/sssoc/n140/0101-6628-sssoc-1400118.pdf. Acesso em: 16 mar. 2021.

SOUZA, D. O. O caráter ontológico da determinação social da saúde. Serv. Soc. Soc., São Paulo, n. 137, p. 174-191, 2020. Disponível em: https://www.scielo.br/pdf/sssoc/n137/01016628-sssoc-137-0174.pdf. Acesso em: 21 maio 2020.

TANURE, C.; MELGAÇO, N.; ALBUQUERQUE, R. Direito à Informação. In: ALBUQUERQUE, A.; ELER, K. (Coord.) Direitos humanos dos pacientes e COVID-19. Brasília: Observatório dos Direitos dos Pacientes / PPGB-UnB; UFJF; UNESCO, abr. 2020, p. 15-17. Disponível em: http://www.observatoriopaciente.com.br/wp-

content/uploads/2020/05/direitos_humanos_pacientes_covid_impressao.pdf. Acesso em: 27 jun. 2020.

TONET, I. Expressões socioculturais da crise capitalista na atualidade. In: CONSELHO FEDERAL DE SERVIÇO SOCIAL. CFESS; ASSOCIAÇÃO BRASILEIRA DE ENSINO E PESQUISA EM SERVIÇO SOCIAL. ABEPSS. (Org.) Serviço Social: direitos sociais e competências profissionais. Brasília: CFESS; ABEPSS, 2009, p. 107-124. 
UMA pessoa muito trabalhadora, diz sobrinho de empregada doméstica que morreu de coronavírus. G1, Fantástico, São Paulo, 22 mar. 2020. Disponível em: https:/g1.globo.com/fantastico/noticia/2020/03/22/uma-pessoa-muito-batalhadora-dizsobrinho-de-empregada-domestica-que-morreu-de-coronavirus.ghtml. Acesso em: 6 fev. 2021.

VASCONCELOS, A. M. Serviço Social e práticas democráticas na saúde. In: MOTA, A. E. et al. (Org.) Serviço Social e Saúde: Formação e trabalho profissional. São Paulo: Cortez, 2006, p. 242-272.

Letícia Batista Silva Trabalhou na concepção do artigo, análise e interpretação dos dados, redação do artigo e aprovação da versão final e ser publicada.

Doutora em Serviço Social pela UERJ, Mestre em Serviço Social pela UFRJ, Especialização em Gestão de Serviços e Sistemas de Saúde pela ENSP/FIOCRUZ e Graduação em Serviço Social pela UNISINOS/RS. Pesquisadora em Saúde Pública Associada da Escola Politécnica de Saúde Joaquim Venâncio da Fundação Oswaldo Cruz (EPSJV/FIOCRUZ). E Professora Adjunta da Escola de Serviço Social da Universidade Federal Fluminense UFF/Niterói. Membro Pesquisadora do Núcleo Interinstitucional de Estudos e Pesquisas sobre Teoria Social, Trabalho e Serviço Social - NUTSS.

Marina Monteiro de Castro e Castro Trabalhou na análise e interpretação dos dados; redação do artigo e aprovação da versão final a ser publicada.

Doutora em Serviço Social pela UFRJ, Mestre em Serviço Social pela UFJF. Professora adjunta da Faculdade de Serviço Social da Universidade Federal de Juiz de Fora (graduação e pós-graduação). Membro do Grupo de Estudos e Pesquisas dos Fundamentos do Serviço Social (GEPEFSS).

Rodriane de Oliveira Souza Trabalhou na análise e interpretação dos dados, na redação e revisão do artigo bem como na aprovação da versão a ser publicada.

Mestre em Serviço Social pela UFRJ, Especialista em Serviço Social e Saúde pela UERJ e Graduada em Serviço Social pela UFRJ. Doutoranda do Programa de Pós-Graduação em Serviço Social da Universidade Federal do Rio de Janeiro (PPGSS/UFRJ). Professora Assistente da Faculdade de Serviço Social da Universidade do Estado do Rio de Janeiro (FSS/UERJ); Pesquisadora do Grupo de Pesquisa Gestão Democrática da Saúde e Serviço Social / Pela Saúde. 